\section{FRI0024 EFFECTIVENESS AND TOXICITY PROFILES OF TRADITIONAL DISEASE MODIFYING ANTIRHEUMATIC DRUGS FOR RHEUMATOID ARTHRITIS}

D Aletaha, JS Smolen. Division of Rheumatology, Department of Internal Medicine III, University of Vienna, Vienna General Hospital, Vienna, Austria

\subsection{6/annrheumdis-2001.1153}

\section{Background}

Objectives To determine the state of application and the fate of traditional disease modifying antirheumatic drugs (DMARDs) during the years before the introduction of new DMARDs including biologic agents.

Methods In a historical prospective analysis the fate of DMARD therapies in 593 patients, comprising a total number of 1319 courses of DMARDs over a period of 2378 patient years, were analysed. DMARD dosages, treatment durations, reasons for discontinuation and adverse events reported by either the patients or physicians as well as CRP and ESR were analysed. Drug retention rates were estimated using Kaplan-Meier-analysis.

Results Methotrexate (MTX), chloroquine (CQ), and sulfasalazine (SSZ) emerged as the drugs most commonly applied during the past 15 years, ${ }^{1}$ whereas gold salts and D-penicillamine (DPA) were used less frequently during the past decade. Three of four therapies had to be terminated for either inefficacy $(37 \%)$ or adverse events $(42 \%) .^{2}$ Patients on high dose therapy had significantly longer median retention rates than those on low dose therapy (SSZ: 34 vs. 7 months; MTX: 73 vs. 39 months). Interestingly, rather than inefficacy, toxicity was the main reason for discontinuation of MTX and SSZ at low doses.

The most commonly encountered adverse events leading to discontinuation were nausea, abdominal pain and rashes (the latter mainly with gold salts and DPA). ${ }^{2,3}$ Median retention rates lasted 36 months).

Conclusion MTX, SSZ and antimalarials became the most commonly used traditional DMARDs for RA. High dose therapy can be continued longer than low dose therapy, and DMARD use is rather limited by toxicity than by inefficacy. Once tolerated, DMARDs can be retained for long periods of time.

\section{REFERENCES}

1 Felson DT, Anderson JJ, Meenan RF. Use of short-term efficacy/toxicity tradeoffs to select second-line drugs in rheumatoid arthritis. A metaanalysis of published clinical trials. Arthritis Rheum. 1992;35:1117-25

2 Fries JF, Williams CA, Ramey D, Bloch DA. The relative toxicity of disease-modifying antirheumatic drugs. Arthritis Rheum. 1993:36:297-306

3 Wolfe F. Adverse drug reactions of DMARDs and DC-ARTs in rheumatoid arthritis. Clin Exp Rheumatol. 1997;15(Suppl 17):S75-81

\section{FRI0025 THE RHEUMATOID ARTHRITIS PATIENT IN THE CLINIC: COMPARING 1319 CONSECUTIVE DMARD THERAPIES}

D Aletaha, IS Smolen. Department of Internal Medicine III, Division of Rheumatology, University of Vienna, Vienna General Hospital, Vienna, Austria

\subsection{6/annrheumdis-2001.1154}

\section{Background}

Objectives Rheumatoid arthritis (RA) patients are prone to receive a series of consecutive disease modifying antirheumatic drugs (DMARDs). This study was performed to reveal possible strategies and treatment patterns with traditional DMARDs in the 1980s and 1990s to serve as a basis for improvement of treatment strategies.
Methods 593 RA outpatients (80.4\% women) from two hospitals who received 1319 consecutive courses of DMARDs (2376 patient years of therapy) were followed from their first presentation throughout the whole course of their disease. Data were collected as dosage, duration of therapy, reason for discontinuation and all adverse effects that had emerged during DMARD treatment. Furthermore, efficacy of individual DMARDs (using CRP and ESR as surrogates) and survival (applying KaplanMeier-estimates) of drug therapy were assessed.

Results Chloroquine (CQ), sulfasalazine (SSZ), and gold compounds (OG, PG) were typical first DMARDs, while penicillamine (DPA), methotrexate (MTX), azathioprine (AZP), cyclosporine (CyA), and combinations were usually used later in the disease course. MTX, SSZ and CQ were the most commonly employed DMARDs throughout the years, ${ }^{1}$ however, SSZ and CQ therapies were mostly followed by MTX. Disease characteristics did not differ between patients with longstanding therapy and those with therapies terminated early. For consecutive DMARDs, there was a decreasing tendency of efficacy (reduction of acute phase response) and of treatment duration (Table $1)$.

\begin{tabular}{llll} 
Abstract FRI0025 Table 1 & & \\
\hline & $\begin{array}{l}\text { CRP reduction } \\
\text { (mg/dl) } \\
\text { (Mean } \pm \text { SD) }\end{array}$ & $\begin{array}{l}\text { ESR reduction (mm/1st } \\
\text { hour) } \\
\text { (Mean } \pm \text { SD) }\end{array}$ & $\begin{array}{l}\text { Duration } \\
\text { (months) } \\
\text { (Mean } \pm \text { SD) }\end{array}$ \\
\hline $\begin{array}{l}\text { 1st DMARD } \\
\text { therapies }\end{array}$ & $-1.3 \pm 3.4$ & $-10.5 \pm 27.5$ & $24.5 \pm 27.7$ \\
$\begin{array}{l}\text { 2nd DMARD } \\
\text { therapies }\end{array}$ & $-0.6 \pm 2.8$ & $-5.7 \pm 23.9$ & $20.4 \pm 23.7$ \\
$\begin{array}{l}\text { 3rd DMARD } \\
\text { therapies } \\
\text { 4th DMARD } \\
\text { therapies } \\
>\text { 4th DMARD } \\
\text { therapies }\end{array}$ & $-0.3 \pm 2.5$ & $-4.7 \pm 20.8$ & $19.8 \pm 22.0$ \\
\hline
\end{tabular}

Acute Phase Response and Duration of Consecutive DMARD Therapies.

Conclusion MTX is the most commonly employed DMARD therapy for RA and is increasingly used as first therapy in newly diagnosed RA. Patients with high disease activity are more often subjected to MTX therapy than to other DMARDs, while those with low activity were more likely to receive SSZ or CQ.

There is a loss of efficacy with increasing number of subsequent therapies. Thus, treatment duration decreases with increasing number of consecutive DMARD therapies.

\section{REFERENCE}

1 Felson DT, Anderson JJ, Meenan RF. Use of short-term efficacy/toxicity tradeoffs to select second-line drugs in rheumatoid arthritis. A metaanalysis of published clinical trials. Arthritis Rheum. 1992;35:1117-25

\section{FRI0026 THERAPEUTIC STRATEGY WITH SODIUM AUROTHIO- MALATE AS FIRST CHOICE DMARD IN EARLY RHEUMATOID ARTHRITIS: PRELIMINARY RESULTS}

${ }^{1} \mathrm{R}$ Sanmartí, 'A Gómez, ${ }^{2} \mathrm{~J}$ Gratacós, ${ }^{2} \mathrm{M}$ Larrosa, ${ }^{1} J \mathrm{D}$ Cañete, ${ }^{1} \mathrm{G}$ Salvador, ${ }^{1} \mathrm{~J}$ MuñozGómez. 'Rheumatology, Hospital Clinic, Barcelona; ${ }^{2}$ Rheumatology, Hospital Del Parc Tauli, Sabadell, Spain

10.1136/annrheumdis-2001.1155 